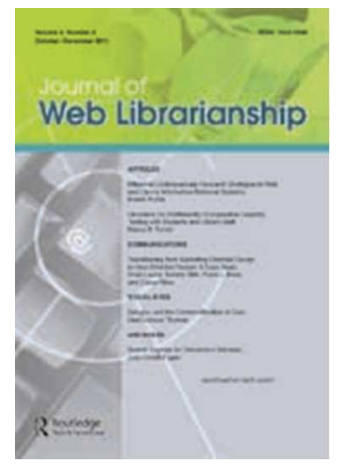

\title{
Metadata quality and academic visibility associated to document type coverage on institutional repositories in Peruvian universities
}

\begin{tabular}{|c|c|}
\hline Journal: & Journal of Web Librarianship \\
\hline Manuscript ID & WJWL-2017-0014.R2 \\
\hline Manuscript Type: & Research Article \\
\hline Keywords: & $\begin{array}{l}\text { Digital repositories, web visibility, metadata, Google Scholar, thesis, } \\
\text { articles, books, Peruvian universities }\end{array}$ \\
\hline Abstract: & $\begin{array}{l}\text { This article analyzes level of metadata quality (MQ ratio) and level of } \\
\text { academic visibility in Google Scholar (IGS ratio) associated with coverage } \\
\text { of four types of documents (theses, articles, books and conferences) in } \\
\text { repositories of Peruvian universities. This research is a cross-sectional } \\
\text { descriptive and correlational study with intentional non-probabilistic } \\
\text { sampling that analyzes } 48 \text { repositories from national }(n=10) \text { and private } \\
\text { universities }(n=38) \text { integrated in the Peruvian National Digital Repository } \\
\text { Alicia (alicia.concytec. gob.pe). Regarding the MQ ratio, we found a median } \\
\text { of } 0.67 \text { [RIC: } 0.552-0.891] \text { for national universities and a median of } 0.65 \\
\text { [RIC: } 0.407-0.838] \text { for private universities }(p=0.542) \text {. Regarding the IGS } \\
\text { ratio, we found a median of } 0.32 \text { [RIC: } 0.241-0.596] \text { for national } \\
\text { universities and a median of } 0.62 \text { [RIC: } 0.464-0.749] \text { for private } \\
\text { universities ( } p=0.054) \text {. The } p \text {-value in Spearman's rank correlation shows } \\
\text { a moderate correlation ( } \rho=0.594 ; \text { p }<0.01) \text { between MQ ratio and the } \\
\text { thesis coverage indicator, and a low correlation }(\rho=0.157) \text { between the } \\
\text { index of document indexing in Google Scholar and the proportion of } \\
\text { documents harvested in Alicia. We conclude that the highest proportion of } \\
\text { academic visibility is concentrated in private universities and the metadata } \\
\text { quality number of items integrated in Alicia favors public universities. }\end{array}$ \\
\hline \multicolumn{2}{|c|}{$\begin{array}{l}\text { Note: The following files were submitted by the author for peer review, but cannot be converted to } \\
\text { PDF. You must view these files (e.g. movies) online. }\end{array}$} \\
\hline $\begin{array}{l}\text { fig01.psd } \\
\text { fig02.psd }\end{array}$ & \\
\hline
\end{tabular}




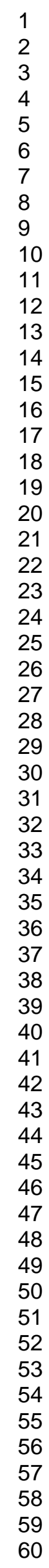

fig03.psd

SCHOLARONE ${ }^{\text {'m }}$

Manuscripts

URL: https://mc.manuscriptcentral.com/jweblib E-mail: jweblib@gmail.com 
FIGURES - Metadata quality and academic visibility associated to document type coverage on institutional repositories in Peruvian universities

Figure 1. Metadata quality ratio by Peruvian universities.

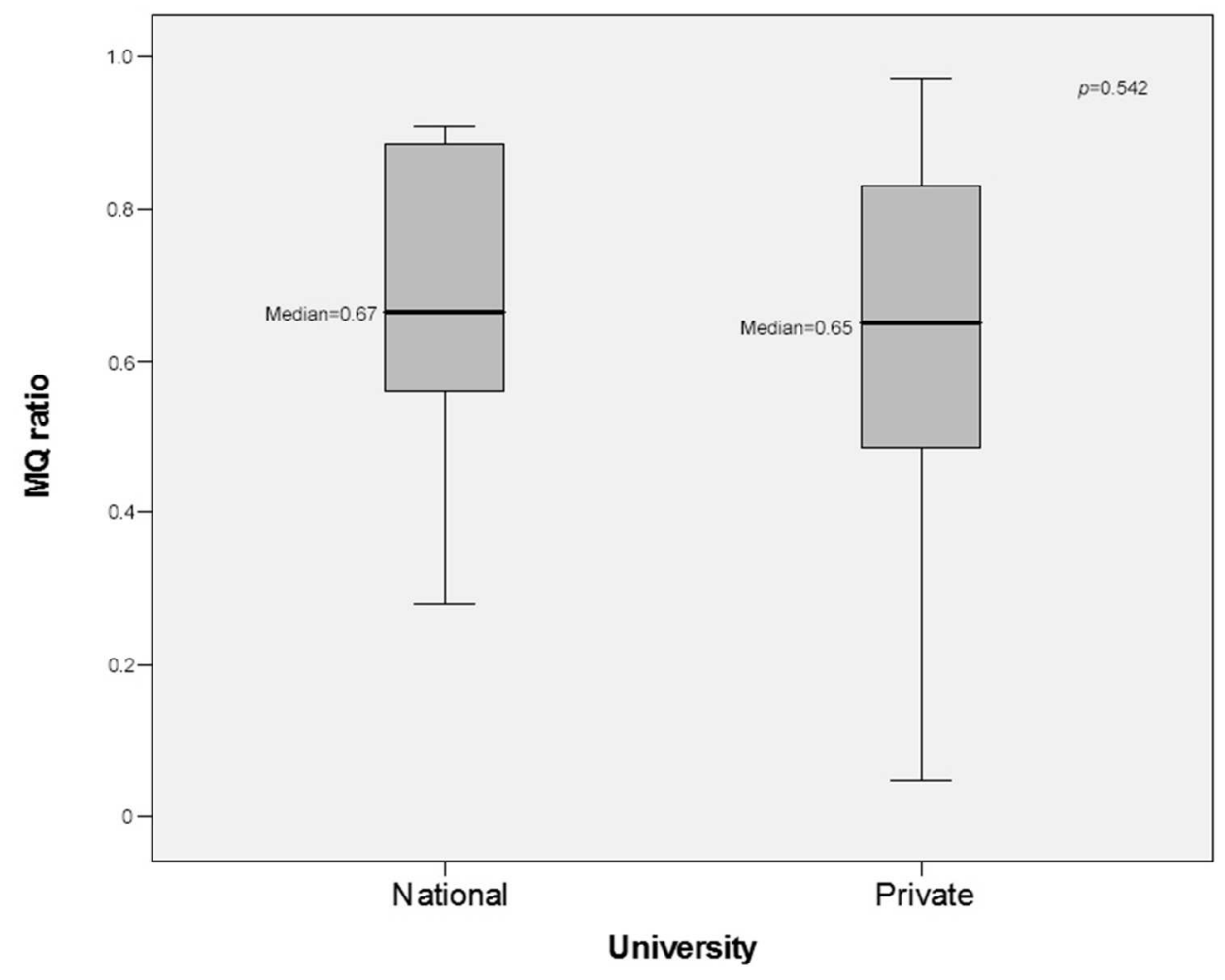

Figure 2. Academic web visibility ratio by Peruvian universities. 


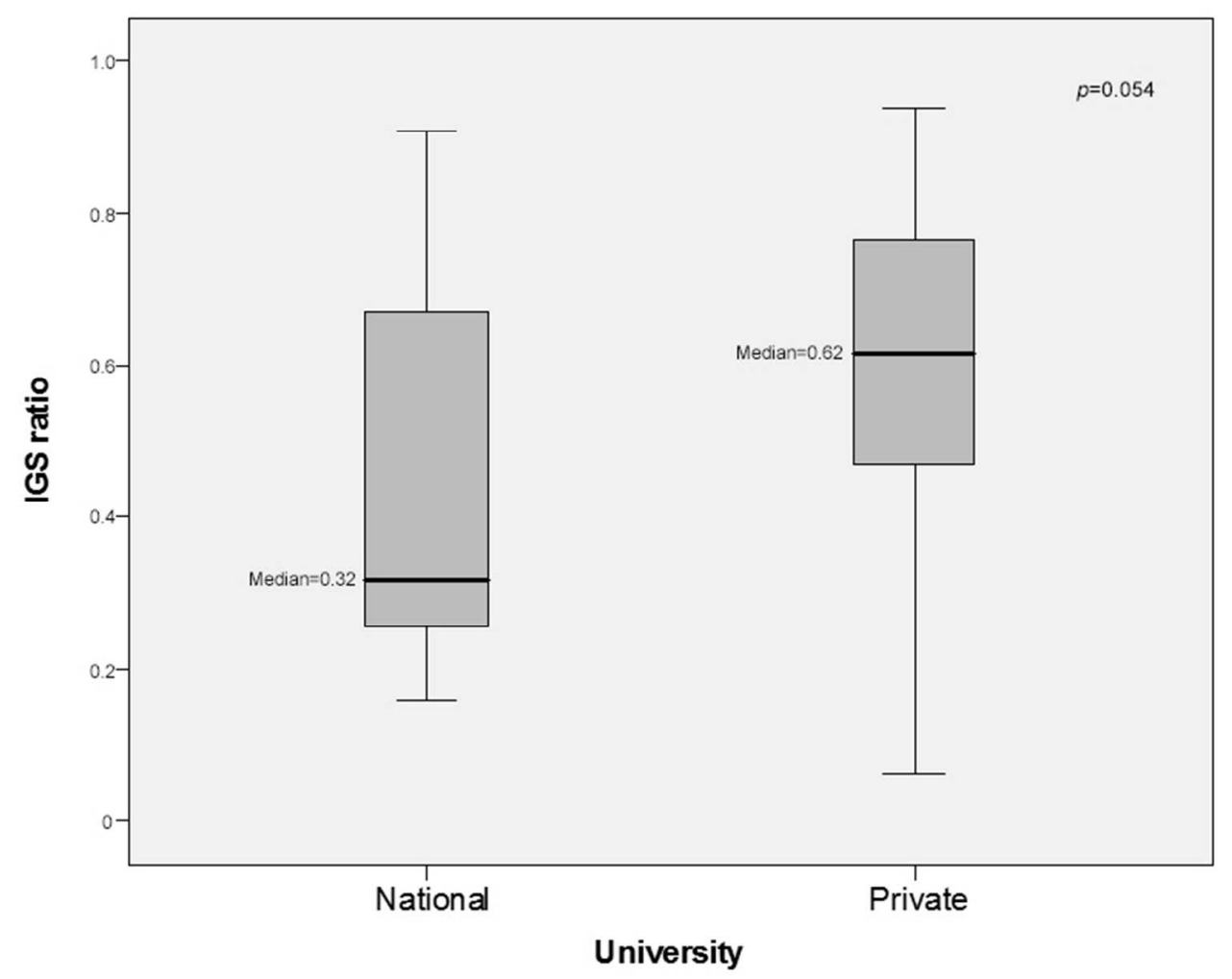

Figure 3. Coverage of document type thesis ratio by Peruvian universities

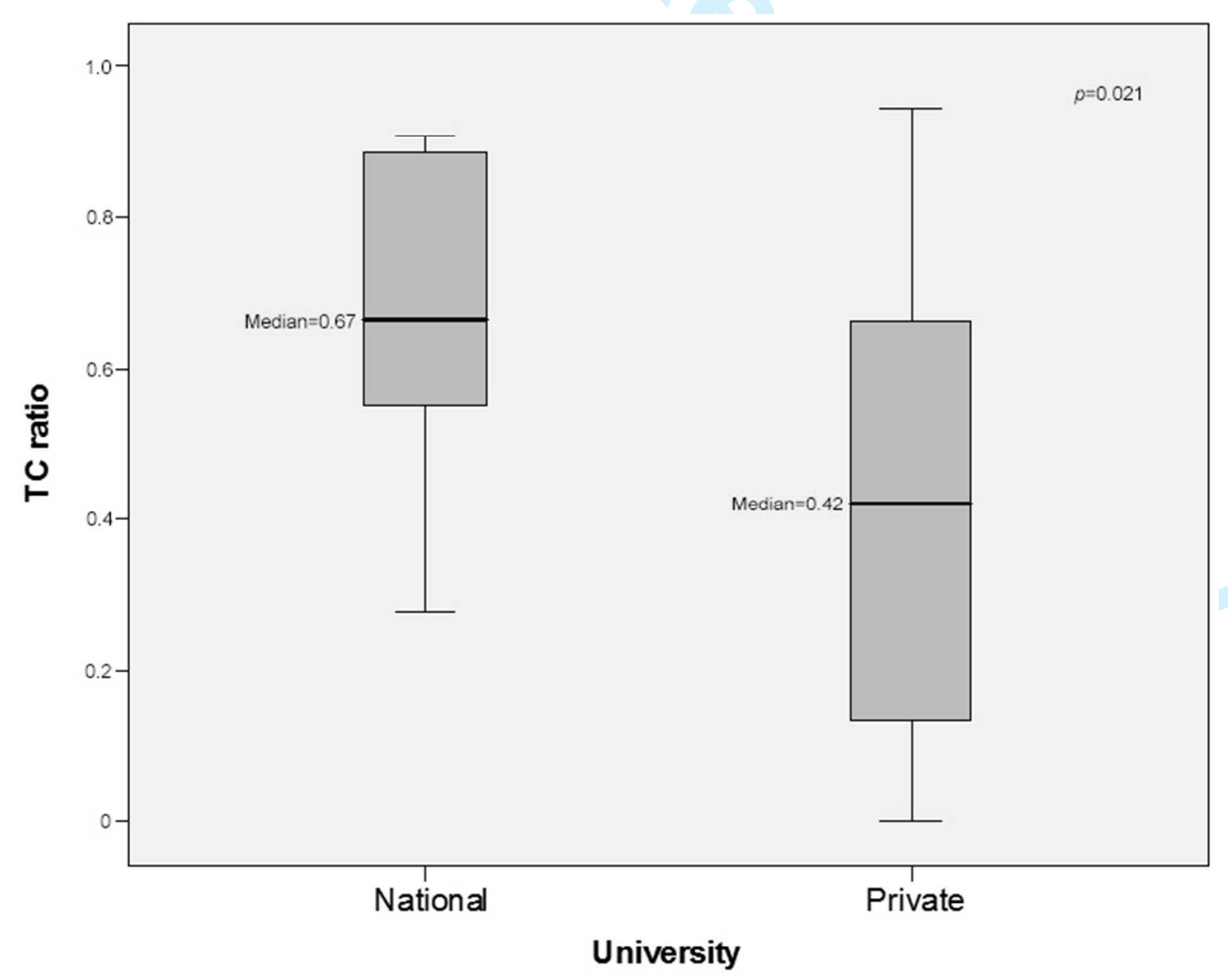

URL: https://mc.manuscriptcentral.com/jweblib E-mail: jweblib@gmail.com 
ES - Metadata quality and academic visibility associated to document type coverage on institutional repositories in Pe universities

10 pfyckage required by CONCYTEC for institutional repositories management 12 taidgata name

Metadata type

cøAtributor.author

Required

coftributor.advisor

tite

dáte.issued

pulblisher

iceentifier.uri

tyoje

laifiguaje.iso

rioghts

rights.uri

sqbject

Required*

Required

Required

Required

Required

Required

Required

Required

Required **

Required

Required

Required

Required

Required*

Required*

Required*

Required*

Required *

Recommended

Optional / Required ***

Optional / Required ***

\section{0}

41

42

43

44

45

46

47

48

49

50

51

52

53

54

55

56

57

58

59

60 


\section{1 \\ 2 \\ 3}

es 4 S.degree.program Recommended*

idgentifier.journal

døsscription.peer-review

Required

Required $^{* * * *}$

ht 9 metadata is Open Access.

imelt type is dataset.

untent type is article.

\begin{tabular}{r}
13 \\
14 \\
15 \\
vel 6 \\
17 \\
18 \\
\hline $\mathbf{y} 19$ \\
20 \\
\hline 21 \\
22 \\
23 \\
24 \\
25 \\
26 \\
27 \\
28 \\
29 \\
30 \\
31 \\
32 \\
33 \\
34 \\
35 \\
36 \\
37 \\
38 \\
39 \\
40 \\
41 \\
42 \\
43 \\
44 \\
45 \\
46 \\
47 \\
48 \\
49 \\
50 \\
51 \\
52 \\
53 \\
54 \\
55 \\
56 \\
57 \\
58 \\
59 \\
60
\end{tabular}

velanalysis by university type.

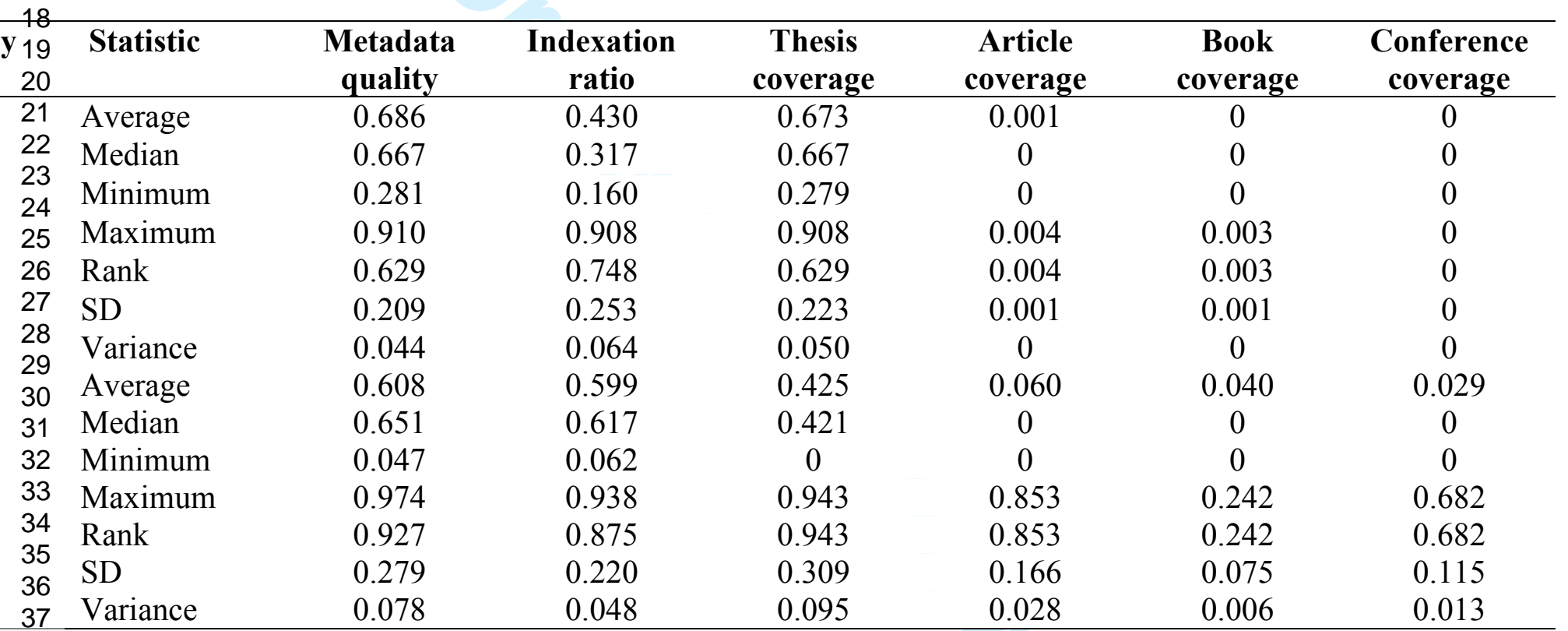

60 


1
2
3
4

1

2

$n$ Gorrelation analysis between study rates

\begin{tabular}{|c|c|c|c|c|c|c|}
\hline Yariable & 1 & 2 & 3 & 4 & 5 & 6 \\
\hline quality & 1 & 0.157 & $0.594^{* *}$ & 0.080 & 0.100 & 0.41 \\
\hline$n 9$ n Google Scholar & & 1 & 0.109 & $-0.340^{*}$ & -0.020 & 0.73 \\
\hline 10 & & & 1 & -0.245 & $-0.457^{* *}$ & -0.220 \\
\hline overage & & & & 1 & $0.432^{* *}$ & 0.301 \\
\hline $\begin{array}{l}\text { verage } \\
14 \\
\text { ceq } \\
\text { foverage }\end{array}$ & & & & & 1 & $\begin{array}{r}0.411 \\
1\end{array}$ \\
\hline
\end{tabular}

it attahe 0.05 level (2-tailed)

int12t the 0.01 level (2-tailed)

18

19

20

21

22

23

24

25

26

27

28

29

30

31

32

33

34

35

36

37

38

39

40

41

42

43

44

45

46

47

48

49

50

51

52

53

54

55

56

57

58

59

60

URL: https://mc.manuscriptcentral.com/jweblib E-mail: jweblib@gmail.com 


\title{
Metadata Quality and Academic Visibility Associated with Document Type Coverage in Institutional Repositories of Peruvian Universities
}

\author{
ALHUAY-QUISPE, Joel* \\ Affiliation: Universidad San Ignacio de Loyola, Lima, Perú. \\ ORCID: http://orcid.org/0000-0002-1903-4687 \\ QUISPE-RIVEROS, David \\ Affiliation: Universidad Nacional Mayor de San Marcos, Lima, Perú. \\ ORCID: https://orcid.org/0000-0002-0518-1512
}

BAUTISTA-YNOFUENTE, Lourdes

Affiliation: Universidad ESAN, Lima, Perú.

ORCID: http://orcid.org/0000-0002-0277-489X

\section{PACHECO-MENDOZA, Josmel}

Affiliation: Universidad San Ignacio de Loyola, Lima,- Perú.

ORCID: https://orcid.org/0000-0002-2251-8092

*Corresponding author:

Email: joel.alhuayq@gmail.com

Address: El Cubo building, 2nd floor. Universidad San Ignacio de Loyola, La Fontana 750 Avenue, La Molina, Lima - Peru.

\section{Abstract}


This article analyzes level of metadata quality (MQ ratio) and level of academic visibility in Google Scholar (IGS ratio) associated with coverage of four types of documents (theses, articles, books and conferences) in repositories of Peruvian universities. This research is a cross-sectional descriptive and correlational study with intentional non-probabilistic sampling that analyzes 48 repositories from national $(\mathrm{n}=10)$ and private universities $(\mathrm{n}=38)$ integrated in the Peruvian National Digital Repository Alicia (alicia.concytec.gob.pe). Regarding the MQ ratio, we found a median of 0.67 [RIC: 0.552-0.891] for national universities and a median of 0.65 [RIC: $0.407-0.838$ ] for private universities $(p=0.542)$. Regarding the IGS ratio, we found a median of 0.32 [RIC: 0.241-0.596] for national universities and a median of 0.62 [RIC: $0.464-0.749$ ] for private universities $(p=0.054)$. The $p$-value in Spearman's rank correlation shows a moderate correlation $(\rho=0.594 ; P<0.01)$ between MQ ratio and the thesis coverage indicator, and a low correlation $(\rho=0.157)$ between the index of document indexing in Google Scholar and the proportion of documents harvested in Alicia. We conclude that the highest proportion of academic visibility is concentrated in private universities and the metadata quality number of items integrated in Alicia favors public universities.

Keywords: Digital repositories; web visibility; metadata; Google Scholar; thesis; articles; books; Peruvian universities.

Main theme: Evaluation of search engine indexing on metadata or digital file formats

\section{Introduction}


The creation of institutional digital repositories is based on their fundamental role as a place to keep documentation (e.g. academic, teaching, institutional, etc.) by an institution that supports the Open Access initiative (Serrano Vicente, Melero Melero, and Abadal 2014), and they are developed from management services related to collection, organization, dissemination and preservation of academic publications in an institution (Costa, 2014), foundations already set out in Berlin (2003) and Budapest statements (BOAI, 2012) of the Open Access movement (OA). In consequence, Chaves (2017) refers to these systems ensuring greater visibility of scientific production and better management of institutional or thematic knowledge.

For the Peruvian case, a pioneering initiative that fostered the creation of institutional repositories was launched, called the Cybertesis Project (October, 2004). It restricted the publication of one type of document: theses. As Cerda (2016) says, Central Library "Pedro Zulen" presented the Cybertesis Project to Universidad Nacional Mayor de San Marcos (UNMSM) in 2001, and it was approved in 2002 under a rectoral resolution. This project was intended to host electronic theses produced by the UNMSM, the oldest university in South America and the most important Peruvian public university.

Cybertesis Project started with the cooperation among the University of Montreal (Canada), University of Lyon (France), University of Chile, and was replicated in Peru by the UNMSM, which in turn led the project and allowed its development in other Peruvian universities (Vílchez-Román and Nakamura Shimabukuro 2008). The application of the Cybertesis methodology allowed access to full text in two file formats: PDF and HTML. Also, it enabled automatic generation of XML files to ensure the conservation and preservation of digital theses.

Then, given evolution platforms and the adoption of policies and good practices, and other notable cases were influenced by the Cybertesis Project. Repository of the Pontificia Universidad Católica del Peru (PUCP) was launched in 2013 (Yañez, 2014), an ambitious project under the responsibility of the Technical Advisory Rector's Office that started in 2010 .

In 2013, the Academic Repository of the Universidad Peruana de Ciencias Aplicadas (UPC) was released (Eléspuru 2016). This repository uses Open Repository (OR) as a platform, which is a modification of DSpace (version 5), the Handle system as a persistent identifier, the protocol for content transmission (OAI-PMH) and Dublin Core metadata (qualified).

After this period of initiatives and good practices in several universities, the National Repository Law (Congress of the Republic, Peru 2013) is published. This law regulates the National Digital Repository of Science, Technology and Technological Innovation.

\section{Metadata Management in Digital Repositories}


There are several standards for metadata management in digital repositories. Otto (2014) identifies those 54 repositories from the Association of Research Libraries (ARL) using Qualified Dublin Core, Simple Dublin Core, Metadata Object Description Schema (MODS), PREMIS, NISO MIX (Z39.87) and MARC as standardized instruments to describe their digital objects deposited.

Dublin Core (DC) is a set of elements or properties that allows the semantic description of a wide range of information resources in the web, which allows registering and retrieving books, theses, research projects, conference presentations, multimedia documents, etc. (Dublin Core Metadata Initiative 2017). The so-called simple Dublin Core (unqualified) is the one originally used to describe resources and digital objects using 15 metadata: dc: title, dc: creator, dc: subject, dc: description, dc: publisher, dc: contributor, dc: date, dc: type, dc: format, dc: identifier, dc: source, dc: language, dc: relation, dc: coverage, dc: rights (Becerril García, Lozano Espinosa, and Molina Espinosa 2016)

Metadata management with Dublin Core in digital repositories implemented with platforms such as Dspace allows the interoperability between systems, migration (import and export) from traditional bibliographic description systems such as MARC (Machine Readable Cataloging) (Walsh 2011).

The adoption of a standard in metadata management ensures interoperability between technological platforms, through information transfer protocols such as Open Archives Initiative (OAI-PMH) for Metadata Harvesting. This protocol appears with the Open Archives Initiative published in 1999, whose first public version was in 2001, due to the need to convert files into interoperable files and build information retrieval services from many repositories (Becerril García, Lozano Espinosa, and Molina Espinosa 2016). In that sense, Open Access digital repositories have implemented the OAI protocol as a mechanism to achieve interoperability in the exchange of meta-information with other systems such as the metadata harvesters (Bueno-De-La-Fuente et al. 2009).

\section{Interoperability between Peruvian Institutional Repositories}

Most Peruvian institutional repositories were implemented under the DSpace platform, and only one in the Open Repository (University of Nottingham 2017). DSpace was created mainly to accommodate institutional repositories that use the Dublin Core standard to register metadata that can also be imported using an XML Scheme (Barroso, Azevedo, and Ribeiro 2009).

The Peruvian National Repository Alicia (Free Access to Scientific Information) is a National Digital Repository of Science, Technology and Innovation of Peru, and it was operational on May 6, 2014 by means of Law No. 30035 dated June 5, 2013. This law regulates the National Digital Repository of Science, Technology and Technological Innovation of Open Access 
(Congress of the Republic. Peru 2013). It integrates public and private higher education institutions, as well as non-governmental organizations and state agencies.

It was initially implemented in Open Knowledge Harvester Systems (https://pkp.sfu.ca/ohs) of the Public Knowledge Project (May 2014 - February 2015), and then it adopted the technology of VuFind (https://vufind.org/), developed and maintained by Memorial Falvey Library of the University of Villanova (the first two months of 2015). Vufind is based on Apache Solr search and on Java, using an index instead of a relational database, thereby enabling faster data retrieval (Katz and Nagy 2014).

Alicia is the national node, which together with other national harvesters in Latin America, joins the regional collector project called "La Referencia" (Federated Network of Institutional Repositories of Scientific Publications of Latin America).

Peru, for its participation in the La Referencia Project, through CONCYTEC (National Committee in Science, Technology and Technological Innovation) adopted Dublin Core as a standard for metadata management and DRIVER Guidelines 2.0 as guidelines for exposing textual resources with OAI-PMH protocol. Both guidelines adopted by CONCYTEC are aimed at managers and administrators of digital repositories, who are responsible for the fulfillment of the requirements for the incorporation of institutional repositories into the Digital National Repository (Alicia).

In that sense, universities with an institutional repository implemented and managed under Dublin Core and Driver 2.0 guidelines, and which ask CONCYTEC their inclusion in Alicia, undergo an evaluation process of three points:

a) Configuration: Installation and configuration review of DSpace according to suggested technical aspects.

b) Metadata: Verification of metadata quality registered by each item published according to document type (Table 1).

c) Content: It verifies that document content is equal to the metadata registered.

\section{[PLACE TABLE 1 HERE]}

By March 2017, Alicia included more than 61,000 records from 94 integrated institutions, of which 69 belong to universities and 25 to non-governmental and state institutions (National Committee in Science, Technology and Technological Innovation. Peru, 2017)

\section{Google Scholar as an Academic Visibility Tool}

For purposes of research, the coverage of theses and other types of documents such as articles, books and conferences will be taken into account. In the specific case of research works (thesis), they should be available, according to the New University Law 30220, in the repository of the National Registry of Research (RENATI), which uses this information from Alicia (Congress of the Republic. Peru. 2014).

According to different works developed in Google Scholar (appeared since 2004), it is one of 
the first options and main tools used by a great group of researchers who look for information in the web, as stated by Orduña-Malea (2014). It should be borne in mind that Google and Google Scholar have become the gateway for users searching for academic information.

Google Scholar is often used in the same proportion as classic catalogs of libraries or other specialized search engines. It is important to point out that for the institutional repository to have presence in Google Scholar, it depends on the metadata scheme used, the technological platform and the criteria and strategies applied for that purpose (Orduña-Malea, 2014).

Google Scholar is often used in the same proportion as classic catalogs of libraries or other specialized search engines. But it is important to point out that for the institutional repository to have presence in Google Scholar, it depends on the metadata scheme used, the technological platform and the criteria and strategies applied (Orduña-Malea, 2014); although, in some cases Google Scholar discover few or nothing PDF files published in digital collections (Yang, 2016)

Regarding information retrieval, Google Scholar crawlers systematically analyze the entire academic web, without making distinctions between thematic areas, languages or countries, allowing the estimate of impact metrics for a wider collection of documents (Martin-Martin 2016). Under these considerations, GS is considered as the means of data analysis.

An important reference in the research on the IR in GS of the publications managed in digital repositories is of Arlitsch and O'Brian (2012), who among other subjects, had obtained as a result with the indexation in GS that: whether the IR has provided crawlers an efficient method to access its scholarly papers; and whether acceptable metadata schemas are provided that offer precise bibliographic information within the HTML page header tags.

Taking into account these experiences, and the current context in Peru regarding publications in institutional repositories and the popularity and validity of GS as tool used by researchers, and as a reference of web presence of scientific production of an academic institution, it is which takes into account the importance of retrieval analysis in GS of a particular publication type: theses.

\section{Objectives}

This article aims to analyze metadata quality degree (which we call the MQ ratio) and academic visibility level in Google Scholar (which we call IGS ratio) associated with the coverage by four document types (theses, articles, books and conferences) from 48 institutional repositories of Peruvian public and private universities integrated in the Peruvian National Digital Repository called Alicia.

The study aims to approximate that proportion of metadata quality is associated with only one document type (thesis) over others (articles, books). That is, the number of documents incorporated in repositories and that are harvested into Alicia are predominantly theses. The national situation of the education quality evaluation led to the creation of National Repository of Research Works - RENATI.

As a general focus, this research aims to answer:

URL: https://mc.manuscriptcentral.com/jweblib E-mail: jweblib@gmail.com 
- Is the relationship between MQ ratio and TC ratio significant?

- Is the relationship between IGS ratio and MQ ratio significant?

- Is the difference between private and public universities for MQ ratio significant?

- Is the difference between private and public universities for IGS ratio significant?

- Is the difference between private and public universities for TC ratio significant?

\section{Methodology}

\section{Methods.}

Cross-sectional descriptive and correlational study with non-probabilistic intentional sampling.

\section{Units of Analysis}

According to the analysis, there are 69 repositories (supplementary material) from public and private universities integrated in Alicia (alicia.concytec.gob.pe). Of them, only 48 repositories from national $(n=10)$ and private universities $(n=38)$ were selected according to two inclusion criteria:

- University with institutional or digital theses repository in Alicia.

- Repository site available at the time of collection data.

\section{Data Collection}

Several studies focused on analysis and evaluation repositories, such as the study made by Sandy and Dykas (2016) that analyzes the metadata quality in repositories from US, or such as the study conducted by Roy, Biswas, and Mukhopadhyay (2016) that analyzes global repositories in LIS domain, taking OpenDOAR as a data source for sampling. OpenDOAR is an authoritative directory of academic Open Access repositories, because each repository listed has been revised by OpenDOAR project staff in order to check the information recorded (University of Nottingham, 2014). However, we note that the portal has been discontinued since April 2014, for that reason, we do not considered it as a data source.

The World Repositories Ranking Webometrics, initiative of Cybermetrics Lab, a research group belonging to the CSIC (Spanish National Research Council, 2017), despite being a source that uses rigorous indicators of repository evaluation and presents semi-annual update (January and July), we note that many Peruvian university repositories are not fully represented.

For these reasons, and because this research evaluates institutional repositories of Peruvian universities, we use National Harvester Alicia as a data source. We also use it because repositories included in Alicia were evaluated at metadata quality level, which is an indicator of measure in this article.

Data was collected on March 26, 2017.

\section{Data Processing and Analysis}

Three indicators were used as evaluation criteria: metadata quality, Google Scholar indexing, 
and document type coverage. Each indicator of analysis was derived from dividing two data:

$$
\mathrm{MQ}_{\mathrm{r}}=\# \text { items in Alicia/ \#items in Repository... (1) }
$$$$
\mathrm{IGS}_{\mathrm{r}}=\text { \#items in GS / \#items in Repository... (2) }
$$$$
\mathrm{DC}_{\mathrm{r}}=\text { \#items in Alicia/ \#items in Repository... (3) }
$$

Where:

MQ: Metadata quality ratio.

IGS $_{\mathrm{r}}$ : Indexing in Google Scholar ratio.

$\mathrm{DC}_{\mathrm{r}}$ : Document thesis coverage ratio.

Records counts in every repository (\#items in Repository) correspond to the number of documents found at query time of data collection. The query was performed using an advanced search interface of the system.

The number of records harvested in Alicia (\#items in Alicia) corresponds to the number of documents displayed in the National Repository portal for each institution and only by the institutional repository, excluding journal repositories.

From records counted as items in Alicia, the number of thesis documents (\#items theses in Alicia) was identified with "format" filter of the National Repository portal. Three thesis-type documents were considered for this count: bachelor thesis, master thesis and doctoral thesis.

The number of documents indexing in Google Scholar (\#items in GS) for each analyzed repositories was extracted by direct queries in search engines using the command "site" with web address of the repository (e.g.: site: repository.domain.edu.pe).

To determine normality assumption in indicators (1), (2) and (3), we use Shapiro-Wilk test for samples $<50$ cases. Normality test showed that values of analysis indicators were not distributed in a normal way, so we use Mann-Whitney's U Test, non-parametric equivalent of T-Test for the difference of two means in independent samples with assumptions of nonnormality in populations.

Finally, to analyze the association between study variables, we use Spearman rho correlation coefficient after identifying non-normal distribution of ratios.

\section{Results}

\section{Descriptive Analysis}

The measure of central tendency of metadata quality is higher in national (media $=0.686$ ) than in private (media $=0.608$ ) universities, However, the standard deviation shows us that they are not statistically different.

[PLACE TABLE 2 HERE]

\section{Metadata Quality}


Metadata quality ratio (MQ ratio) shows a median of 0.67 [RIC: 0.552 - 0.891] for national universities and 0.65 [RIC: $0.407-0.838$ ] for private universities with a statistically nonsignificant difference (Mann-Whitney's U Test: $p$-value=0.542).

\section{[PLACE FIGURE 1 HERE]}

\section{Web Visibility}

Indexing in Google Scholar (IGS ratio) shows a median of 0.32 [RIC: 0.241 - 0.596] for national universities and 0.62 [RIC: $0.464-0.749$ ] for private universities with a statistically non-significant difference Mann (Whitney U Test: $p$-value=0.054).

\section{[PLACE FIGURE 2 HERE]}

\section{Coverage of Document Type, Thesis}

Thesis coverage ratio shows a median of 0.67 [RIC: $0.494-0.891$ ] for national universities and 0.42 [RIC: $0.115-0.679$ ] for private universities; However, for this indicator, there is a statistically significant difference (Mann Whitney U Test: $p$-value=0.021).

\section{[PLACE FIGURE 3 HERE]}

\section{Correlation Analysis}

The correspondence analysis based on Spearman's rho between MQ and IGS ratio, and three indicators of coverage per document type (thesis, article, book, conference) for all sample repositories shows a moderate correlation $(\rho=0.594 ; p<0.01)$ between metadata quality and a document type indicator: thesis. In addition, Table 3 shows that there is a low correlation ( $\rho$ $=0,157$ ) between the indexing of documents in Google Scholar and the proportion of documents harvested in Alicia, with respect to the number of documents in the source repository.

\section{[PLACE TABLE 3 HERE]}

On the other hand, the results show there is a moderate correlation between several types of coverage, such as article and book $(\rho=0.432, \mathrm{P}<0.05)$ and book and conference $(\rho=0.411)$. However, there is no association between coverage of type of document and indexing ratio in Google Scholar.

\section{Discussion and Conclusions}

Private universities show the highest number of items indexing in Google Scholar (60\%) compared to public universities (43\%), which evidences that there is more work at content visibility level in the private sector. However, the number of items deposited in public university repositories oversteps the number of items housed in a private university repository. In general, it is known that Google Scholar does not index all resources, for example, Orduña-Malea et al (2014) found that of 127 repositories, only 34\% is indexed in google scholar and in the case of PDF files, the number is smaller, reaching only $2.5 \%$. Also, Orduña-Malea and Delgado López-Cózar (2015) mention that 137 repositories (132 of them were institutional) have low indexing ratios and explain that these low ratios are due to the use of schemas of description that are not suitable for Google Scholar and to the use of 
unsuitable web navigability.

In both cases, around half the repositories analyzed showed low indexing ratios in GS, which could indicate two points: a) lack of awareness or underestimation of web visibility that can be obtained by the institutional repository from Google Scholar (GS), or b) restriction of access (restricted or embargoed) to thesis, especially in private universities because these document types belong mostly to business sciences.

On the other hand, Alicia does not allow indexing its harvested records in Google Scholar, which could corresponds to a limited capacity of its computer components since constant queries of Google bots and crawlers would generate an increase of logs that supposes a greater capacity of requirements in the server.

The proportion of items integrated into Alicia with respect to all repository items in public $(69 \%)$ and private universities $(61 \%)$ indicates that about half the items deposited in repositories do not meet CONCYTEC metadata quality requirements or they are document types non-contemplated for harvesting in Alicia.

Most coverage of documents from public and private universities integrated in Alicia are theses, followed by other types of documents such as articles, books and conferences. That could indicate that many Peruvian universities implement their institutional repositories to meet the requirements of national organisms like SUNEDU or CONCYTEC, but not to manage and disseminate research, and because it is an opportunity for institutional collaboration, search funds and institutional prestige improvement.

Declaration of possible conflicts of interests: $D Q R$ at the time of the research was working at CONCYTEC.

\section{Supplementary material:}

Additional information of institutional repositories analyzed is available in https://doi.org/10.6084/m9.figshare.5413231.v1

\section{References}

Arlitsch, Kenning, and Patrick S. O’Brian. 2012. "Invisible institutional repositories: addressing the low indexing ratios of IRs in Google". Library Hi Tech, 30(1), 6081.doi: $10.1108 / 07378831211213210$

Barroso, Isabel, Azevedo, Marta, and Cristina Ribeiro. 2009. "Thematic Digital Libraries at the University of Porto: Metadata Integration over a Repository Infrastructure." In Lecture Notes in Computer Science (Including Subseries Lecture Notes in Artificial Intelligence and Lecture Notes in Bioinformatics), 5714 LNCS:392-95. Corfu, Greece. doi:10.1007/978-3-642-04346-8_42.

Becerril García, Arianna, Rafael Lozano Espinosa, and José Martín Molina Espinosa. 2016. "Semantic Approach to Context-Aware Resource Discovery over Scholarly Content Structured with OAI-PMH." Computación y Sistemas 20 (1): 127-42. doi:10.13053/cys-20-1-2189.

Bueno-De-La-Fuente, Gema, Hernández-Pérez, Tony, Rodríguez-Mateos, David, Méndez- 
Rodríguez, Eva M., and Bonifacio Martín-Galán. 2009. "Study on the Use of Metadata for Digital Learning Objects in University Institutional Repositories." In ELPUB 2009 - Rethinking Electronic Publishing: Innovation in Communication Paradigms and Technologies - Proceedings of the 13th International Conference on Electronic Publishing, 587-94. Milan, Italy.

BOAI. 2012. "Budapest Open Access Initiative". http://www.budapestopenaccessinitiative.org/

Cerda Cosme, Roxana. 2016. “Cybertesis Perú, evaluación del repositorio de tesis de la Universidad Nacional Mayor de San Marcos". Thesis degree in Library and Information Science. Universidad Nacional Mayor de San Marcos, Peru. http://cybertesis.unmsm.edu.pe/handle/cybertesis/5795

Congress of the Republic. Peru. 2013. Ley $N^{\circ}$ 30035. Ley Que Regula el Repositorio. Nacional Digital de Ciencia, Tecnología e Innovación de Acceso Abierto.

Congress of the Republic. Peru. 2014. Ley $N^{\circ}$ 30220. Ley Universitaria.

Café, Chaves Luísa, and Ivette Kafure Kafure. 2017. "Evaluación de la Usabilidad del Repositorio Institucional de la Universidad de Brasília”. Revista General de Información y Documentación, 27(1), 87-106. doi:10.5209/RGID.56563

Dublin Core Metadata Iniciative. 2017. "Dublin Core.” http://dublincore.org/.

Eléspuru Briceño, L., \& Huaroto, L. 2016. "Los repositorios institucionales como herramientas para medir los indicadores Altmetrics: experiencia de la Universidad Peruana de Ciencias Aplicadas (UPC)". In V Congreso Internacional de Bibliotecas Universitarias CIBU 2016: Las Bibliotecas y su rol en la creación de conocimiento. Lima, Peru. http://repositorioacademico.upc.edu.pe/upc/handle/10757/617434

Katz, Demian, and Andrew Nagy. 2014. "VuFind: Solr Power in the Library." In Open Source Technology: Concepts, Methodologies, Tools, and Applications, 3-4:1454-79.

Martín-Martín, Alberto, Orduña-Malea, Enrique, Ayllón, Juan M., and Emilio Delgado López-Cózar. 2016. "Un panorama académico de dos caras: retrato de los documentos altamente citados en Google Scholar (1950-2013)". Revista Española de Documentación Cientifica, 39(4), 149. doi:10.3989/redc.2016.4.1405

Orduña-Malea, Enrique, and Emilio Delgado López-Cózar. 2014. "The dark side of open access in google and google scholar: The case of latin-american repositories". Scientometrics; 102(1):829-46. doi: 10.1007/s11192-014-1369-5.

Orduña-Malea, Enrique, Martín-Martín, Alberto, Ayllón Millán, Juan Manuel, and Emilio Delgado López-Cózar. 2014. “Are Latin-American repositories invisible on Google and Google Scholar?”. EC3 Google Scholar's Digest Reviews, (3). http://hdl.handle.net/10481/32363

National Committee in Science, Technology and Technological Innovation. Peru. 2017. “Alicia.” Repositorio. Nacional Digital de Ciencia, Tecnología E Innovación de Acceso Abierto. http://alicia.concytec.gob.pe

Otto, Jane Johnson. 2014. "Administrative Metadata for Long-Term Preservation and Management of Resources: A Survey of Current Practices in ARL Libraries.” Library Resources and Technical Services 58 (1): 4-32. doi:10.5860/1rts.58n1.4.

Roy, Bijan Kumar, Subal Chandra Biswas, and Parthasarathi Mukhopadhyay. 2016. "Global

URL: https://mc.manuscriptcentral.com/jweblib E-mail: jweblib@gmail.com 
Repository Movement in the Domain of Library and Information Science Discipline." International Journal of Information Science \& Management 14 (2): 15-32. https://ijism.ricest.ac.ir/index.php/ijism/article/view/788/288

Sandy, Heather Moulaison, and Felicity Dykas. 2016. "High-Quality Metadata and Repository Staffing: Perceptions of United States-Based OpenDOAR Participants". Cataloging and Classification Quarterly 54 (2): 101-16. doi:10.1080/01639374.2015.1116480.

Serrano Vicente, Rocío, Remedios Melero Melero, and Ernest Abadal. 2014. "Indicators for the Evaluation of Open Access Institutional Repositories". Anales de Documentacion 17 (2). doi:10.6018/analesdoc.17.2.190821.

Spanish National Research Council. 2017. "Webometrics. Ranking Web of Repositories" http://repositories.webometrics.info.

University of Nottingham. 2017. "OpenDOAR: Directory of Open Access Repositories." http://www.opendoar.org/.

Vílchez-Román, Carlos, and Diana Nakamura Shimabukuro. 2008. "Usability of a Full Text Information Retrieval System: The Case of Cybertesis Peru." ACIMED 17 (3). http://scielo.sld.cu/scielo.php?script=sci_abstract\&pid=S1024-94352008000300003

Walsh, Maureen P. 2011. "Repurposing MARC Metadata for an Institutional Repository: Working with Special Collections and University Press Monographs". Library Resources \& Technical Services, 55(1), 33-44. doi: 10.5860/lrts.55n1.33.

Yang, Le. 2016. "Making Search Engines Notice: An Exploratory Study on Discoverability of DSpace Metadata and PDF Files". Journal of Web Librarianship, 10(3): 147-160. doi: 10.1080/19322909.2016.1172539

URL: https://mc.manuscriptcentral.com/jweblib E-mail: jweblib@gmail.com 